Kalpa Publications in Engineering
Volume 4, 2022, Pages 90-98
$\begin{gathered}\text { Proceedings of International Sym- } \\ \text { posium on Applied Science } 2021\end{gathered}$

\title{
Light-tissue interactions of low-level laser to support the chronic hepatitis patients
}

\author{
Thien Hau Tran ${ }^{1,2,}{ }^{*}$, Minh Thai Tran ${ }^{1,2}$, Thi Ngoc Dung $\operatorname{Tran}^{1,2}$, Thi Thien \\ $\mathrm{Hoa} \mathrm{Ngo}^{3}$ \\ ${ }^{1}$ Laser Technology Laboratory, Faculty of Applied Sciences, Ho Chi Minh City University of \\ Technology (HCMUT), 268 Ly Thuong Kiet Street, District 10, Ho Chi Minh City, Vietnam \\ ${ }^{2}$ Vietnam National University Ho Chi Minh City, Linh Trung Ward, Thu Duc District, Ho Chi \\ Minh City, Vietnam \\ ${ }^{3}$ Clinic rehabilitation treatment Tan Chau, An Giang Province, Vietnam \\ tthienhau@hcmut.edu.vn
}

\begin{abstract}
In this paper, we present some results obtained from the simulation of low power 633, 780,850 , and $940 \mathrm{~nm}$ laser in the liver by Monte Carlo method, with the model of the liver, consisting of $5 \mathrm{~mm}$ derm, $7 \mathrm{~mm}$ subcutaneous fat, $5 \mathrm{~mm}$ muscle layer. Based on these results, we fabricated devices called "Laser Semiconductor Optoacupuncture and phototherapy Device" using 780 and $940 \mathrm{~nm}$ semiconductor lasers to treat chronic hepatitis. We combined with the doctor in An Giang province to clinical practice for 50 voluntary patients with chronic hepatitis. We used a $650 \mathrm{~nm}$ wavelength intravascular semiconductor laser treatment clinically to provide high-quality blood to the patients' liver. Treating the phototherapy of the skin with two semiconductor laser beams with 780 $\mathrm{nm}$ and $940 \mathrm{~nm}$ wavelengths directly affects the liver from the surface of the abdomen. At the moment, we use the treatment on acupoint with $940 \mathrm{~nm}$ - wavelength laser. A treatment course consists of 20 times for the patients is treated continuously. The patients tested with the ALT and AST before and after treatment with 3 courses. We use the SPSS 23 statistical method to evaluate the outcomes of treatment. The clinical symptoms of the patients such as fatigue, nausea, indigestion, fever, jaundice, yellow eyes almost completely have gone out after treatment. Low-level laser therapy offers a good response in patients with moderate to severe hepatic impairment such as the AST of $56.380 \pm$ 10.162 and $39.260 \pm 4.869$; The ALT of $56.540 \pm 13.580$ and $41,360 \pm 7,488$ for beforeand after treatments, respectively. Low-level laser therapy for patients initially has good results, high therapeutic effectiveness, no catastrophic or side Effects, and the statistical significance is $\mathrm{p}<0.001$.
\end{abstract}

${ }^{*}$ Corresponding author

T.T. Truong, T.N. Tran, T.N. Nguyen and Q.K. Le (eds.), ISAS 2021 (Kalpa Publications in Engineering, vol. 4), pp. 90-98 
This research applied the ethical principles of the Helsinki Declaration in human researches. The research was carried out using non-invasive methods on humans with the regulations of the University of Technology, Vietnam National University Ho Chi Minh City, and the relevant regulations.

\section{Introduction}

Light-tissue interactions are an important aspect of low-level laser therapy. Light-tissue interactions have two main actors: optical radiation and tissue. Low-level laser therapy (LLLT) refers to many types of therapy based on photobiomodulation. A process that causes biological alterations in organisms due to photon interaction with atoms or molecules [1]. LLLT is gaining popularity in a variety of clinical applications [2]. Some studies have shown that LLLT enhances skin wound recovery, reduces pain, and control inflammation [3,4]. Makashova researched the effect of laser therapy in different modes and effects on thermocoagulation in patients with acute viral hepatitis B (AVHB) in 2001. Laser therapy normalizes hemostasis and platelet function. Two laser modes had the same clinical effectiveness. The AVHB patients exposed to laser had intoxication, hemorrhagic phenomena, jaundice, infusion therapy, gone out and hospital stay were shorter in laser therapy. Laser therapy normalizes hemostasis and platelet function [4].

The effects of low-intensity irradiation on the liver mitochondria of normal rats and type 2 diabetic rats were researched in 2008. The effect of laser irradiation on such mitochondria significantly recovers their functional activity that can be explained by changes in the inner membrane mitochondria structure in such circumstances [5].

Băgaliev (2010) had an examination for a group of 59 patients presenting with acute viral hepatitis B. The patients had a single course of pulsed infrared laser irradiation resulted in the improvement of clinical conditions and stabilization of ALAT activity, total and direct bilirubin levels [6].

The effect of low-intensity laser therapy on the cytokine system and the function of vascular endothelium in patients were presented with chronic viral hepatitis by Burduli (2011). The results of using low-concentrated laser irradiation as an element of combined therapy of patients presenting with chronic viral hepatitis have marked beneficial effects on the cytokine system and improved the functional activity of vascular endothelium and its NO-producing capacity [7].

The character of microcirculatory disorders in the patients existing with chronic viral hepatitis, Burduli explains the use of laser irradiation to assess the probability for the adjustment of the associated disorders. Application of laser irradiation as an element of the combined treatment of the patients presenting with chronic viral hepatitis help improvement of microcirculatory disorders [8].

From the above studies, a laser is a tool, which becomes available to help many physicians but before the doctor can use this tool he must select a laser, a radiated power, a dot size, and irradiation time. So we calculated the Monte Carlo simulation to determine the appropriate wavelengths in the treatment. Any model of laser treatment is based on the distribution of light in the tissue [9].

\section{Method}

The Monte Carlo simulation method has been used to solve various problems in the physics of light propagation in biological tissue. The simulation program was written in Borland Delphi 7. After that, we used to perform the propagation of photons in tissue by Monte Carlo simulation method, code modified on Tran Thi Ngoc Dung's source. Monte Carlo simulation is a statistical technique for 
simulating random processes and has been applied to light-tissue interactions under a wide variety of situations $[10,11,12,13,14,15,16]$.The light-tissue interaction is governed by the optical tissue parameters, such as the scattering $\mu_{\mathrm{s}}$, and the absorption $\mu_{\mathrm{a}}$, coefficients, which are wavelengthdependent. The absorption coefficient, which can vary over several orders of magnitude, increases towards the visible wavelengths $[17,18,19]$.

In the red and near-infrared regions with $\lambda>625 \mathrm{~nm}$, the absorption coefficient varies between 0.01 and $0.5 \mathrm{~cm}^{-1}$. On the other hand, the scattering coefficient varies only slightly as a function of the wavelength between 10 and $200 \mathrm{~cm}^{-1}[20,21]$.

\subsection{Optical parameters of liver tissue}

We determined the thickness of the layers based on the DICOM image of the patient (Fig.1). We use a three-layer model of skin tissue to liver consisting of $3 \mathrm{~mm}$-thick derm, $7 \mathrm{~mm}$-thick subcutaneous fat, and $5 \mathrm{~mm}$-thick muscle layer. The thickness of the layers is $15 \mathrm{~mm}$. The optical parameters of different layers corresponding to wavelengths $633,780,850$, and $940 \mathrm{~nm}$ are presented in Table 1 [22, $23,24]$

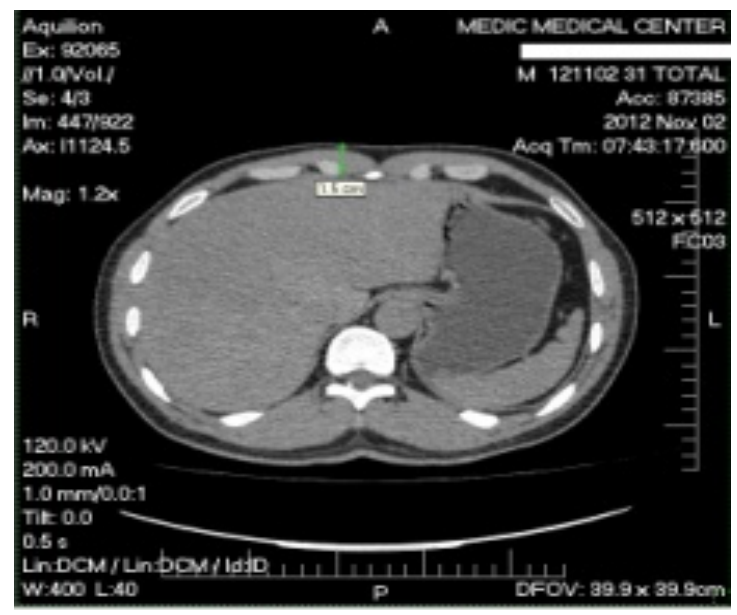

Figure 1: DICOM image of the patient 


\subsection{Simulation results}

\begin{tabular}{lcccc}
\hline \hline \multicolumn{1}{c}{ Wavelength (nm) } & 633 & 780 & 850 & 940 \\
\hline $\begin{array}{l}\text { Absorption coefficient of derm } \\
\left(\mathrm{mm}^{-1}\right)\end{array}$ & 0.03341 & 0.01418 & 0.01223 & 0.01905 \\
\hline $\begin{array}{l}\text { Absorption coefficient of } \\
\text { subcutaneous fat }\left(\mathrm{mm}^{-1}\right)\end{array}$ & 0.013 & 0.0064 & 0.0062 & 0.0042 \\
\hline $\begin{array}{l}\text { Absorption coefficient of muscle } \\
\left(\mathrm{mm}^{-1}\right)\end{array}$ & 0.045 & 0.0057 & 0.0053 & 0.0037 \\
\hline $\begin{array}{l}\text { Scattering coefficient of derm } \\
\left(\mathrm{mm}^{-1}\right)\end{array}$ & 27.29 & 19.74 & 17.57 & 15.68 \\
\hline $\begin{array}{l}\text { Scattering coefficient of } \\
\text { subcutaneous fat }\left(\mathrm{mm}^{-1}\right)\end{array}$ & 1.27 & 4.62 & 4.91 & 4.35 \\
\hline $\begin{array}{l}\text { Scattering coefficient of muscle } \\
\left(\mathrm{mm}^{-1}\right)\end{array}$ & 21.08 & 22.39 & 21.73 & 18.7 \\
\hline Anisotropy of derm & 0.85 & 0.85 & 0.85 & 0.85 \\
\hline Anisotropy of subcutaneous fat & 0.8 & 0.8 & 0.8 & 0.8 \\
\hline Anisotropy of muscle & 0.95 & 0.95 & 0.95 & 0.95 \\
\hline
\end{tabular}

Table 1: The optical parameters of different layers at the abdominal area correspond to wavelengths 633 , 780,850 , and $940 \mathrm{~nm}$.

Fig. 2 present the energy density corresponding to $633,780,850$, and $940 \mathrm{~nm}$. We estimated a characteristic penetration depth of light depth $35,100,120$, and $125 \mathrm{~mm}$ corresponding to the energy density $\times 10^{-4}\left(\mathrm{~W} / \mathrm{Cm}^{2}\right)$. The penetration of $633,780,850$, and $940 \mathrm{~nm}$ can go deeply in the liver at $15 \mathrm{~mW}$ power. The penetration of $850 \mathrm{~nm}$ and $940 \mathrm{~nm}$ are almost the same. biological responses at the target tissue. I occur easily biological responses at the target tissue

\subsection{The clinical treatment device}

Based on the above research, we fabricated the device called "Laser Semiconductor Optoacupuncture and phototherapy Device" (Fig.3) with the following parameters:

- Phototherapy part with two outputs: the wavelengths used $780 \mathrm{~nm}$ and $940 \mathrm{~nm}$, the optical power: $0-18 \mathrm{~mW}$.

- Optoacupuncture part with ten outputs: the wavelengths used $940 \mathrm{~nm}$, the optical power: 0$12 \mathrm{~mW}$.

- The modulation frequency: $5-100 \mathrm{~Hz}$.

- Irradiation time: $5,10,15,20$, and 30 minutes.

- Power supply: AC-120V/50Hz or DC $-12 \mathrm{~V}$ 


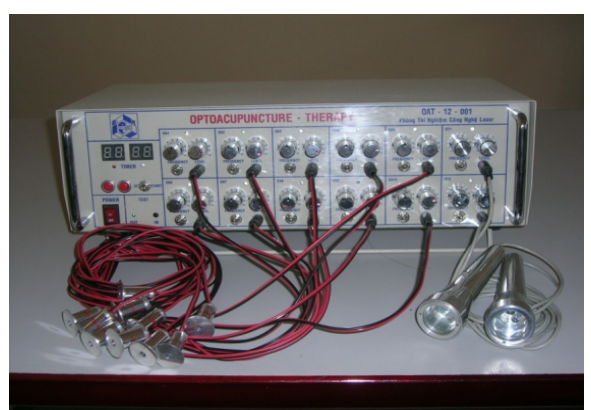

Figure 3 Laser Semiconductor Optoacupuncture and phototherapy Device

- Weight: $1 \mathrm{~kg}$

The two above devices have been researched and manufactured by the Laser Technology Laboratory - Ho Chi Minh City University of Technology.

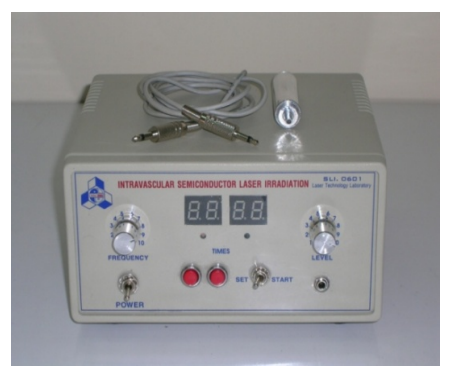

Figure 4: Intravascular semiconductor laser device

\section{Results and Discussion}

\subsection{Clinical results in patients}

\subsubsection{Material}

We combined with the doctor to perform the treatment for patients. The patients included 50 people about the age of 40-54-year-olds twhovolundntarily participated in this clinical experiment. They have many symptoms as nausea, loss of appetite, abdominal pain, fever, jaundice, painful hepatomegaly, splenomegaly. Our research method is a clinical experiment (Fig.5).

\subsubsection{Methods:}

From the above simulation results of low-level laser transmission at different wavelengths, we chose semiconductor laser wavelength of $780 \mathrm{~nm}$ and $940 \mathrm{~nm}$ to create the effect of the two simultaneous wavelengths which impacts directly on the surface of the abdomen skin to the liver and the thymus, spleen and lymph nodes around the liver. From the above simulation results, we chose the semiconductor laser wavelength of $940 \mathrm{~nm}$ to make the Opto-acupuncture needle on acupoints to treat different types of hepatitis and acupuncture points for activating the immune system. 


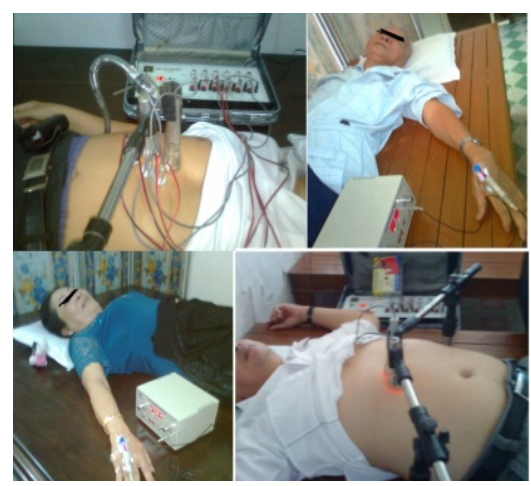

Figure 5 the patient with low level laser therapy in An Giang province

From the studied results in [23, 24, 25], we chose the semiconductor laser of $650 \mathrm{~nm}$ wavelength to perform the intravascular semiconductor laser method. It makes the blood circulation system to the liver and thymus the most sufficiently. When the blood circulation system is improved, it leads to a series of effects on the whole body, as adjusting specific and nonspecific immune, increasing the ability to combine oxygen with hemoglobin, transporting the oxygen in the blood. The patients tested with ALT, AST before and after treatment course with low-power laser therapy.

\subsubsection{The treatment course:}

A treatment course consists of 20 days. On the first day, we used an intravascular semiconductor laser device to perform therapy. On the second day, we treated this disease with Laser Semiconductor Optoacupuncture and phototherapy Device. This treatment cycle is repeated until the end of a therapy course. Treatment once a day, once treatment is $45-60$ minutes.

3.1.4. Experiment:

To evaluate the effectiveness of the clinical experiment, we relied on blood tests before and after treatment. In the liver enzymes: the ALT (Alanine Aminotransferase), also called SGPT, and the AST (Aspartate Aminotransferase), also called SGOT, exist in blood at a low rate. The patients had a blood test with ALT, AST before and after treatment. We use the SPSS 23 statistical method to evaluate outcomes of treatment after 3 courses (60 days) (Statistical Package for the Social Sciences 23).

Table 2. The AST and the ALT before and after treatment

\begin{tabular}{lll}
\hline \hline $\mathrm{n}=50$ & $\begin{array}{l}\text { the AST }(\mathrm{U} / \mathrm{L}) \\
(\bar{X} \pm \mathrm{SD})\end{array}$ & $\begin{array}{l}\text { the ALT }(\mathrm{U} / \mathrm{L}) \\
(\bar{X} \pm \mathrm{SD})\end{array}$ \\
\hline before & $(56.380 \pm 10.162)$ & $(56.540 \pm 13.580)$ \\
\hline after & $(39.260 \pm 4.869)$ & $(41.360 \pm 7.488)$ \\
\hline $\mathrm{p}$ value & $\mathrm{p}<0.001$ & $\mathrm{p}<0.001$ \\
\hline \hline
\end{tabular}

From table 2, we find that the AST and the ALT of the patient decreased significantly and they become normal after treatment. Statistical analysis of liver enzymes according to the Anova method showed that $\mathrm{p}<0.001$. The symptoms of patients: nausea, loss of appetite, abdominal pain, fever, jaundice completely disappeared. 


\subsection{Discussion}

The LLLT is more than an alternative kind of treatment; it is a whole new method to control cells and organisms by precise alterations in molecules. The LLLT empowers contemporary clinicians with a modern and transdisciplinary way to fight against diseases and other undesired conditions in humans and other animals. Moreover, it is a way to stimulate or inhibit some biological processes in all kinds of known living creatures, since LLLT acts in cell respiration.

\section{Conclusion}

Clinical applications of low-power laser therapy are diverse. The subject is illustrated by a variety of approaches and uses of various light sources (lasers, LEDs) with different parameters (wavelength, output power, continuous-wave or pulsed operation modes, pulse parameters).

From the results obtained by simulating the propagation of photons in liver tissue, the contributions of this paper such as the effect of the two simultaneous wavelengths $780 \mathrm{~nm}$ and $940 \mathrm{~nm}$ in therapeutic devices to regenerate and rehabilitate the liver damages of the patients which is a promising alternative treatment method. This thing can recommend us the possibility to use infrared low power laser to treat diseases.

\section{Conflicts of Interest}

The authors declare no conflicts of interest.

\section{Acknowledgment}

Sincere thanks to the doctors who have been so helpful to carry out the clinical trial treatment. We would like to thank Ho Chi Minh City University of Technology (HCMUT), VNU-HCM for the support of time and facilities for this study.

\section{References}

[1] F. Kamali, "The therapeutic effect of low-level laser on repair of osteochondral defects in rabbit knee," Journal of Photochemistry and Photobiology B: Biology, vol. 88, no. 1, pp. 11$15,2007$.

[2] A. R. Medrado, "Influence of low level laser therapy on wound healing and its biological action upon myofibroblasts," Lasers in surgery and medicine, vol. 32, no. 3, pp. 239-244., 2003.

[3] J. M. e. a. Bjordal, "A systematic review of low level laser therapy with location-specific doses for pain from chronic joint disorders," Australian journal of physiotherapy, vol. 49, no. 2, pp. 107-116, 2003.

[4] V. M. VV Makashova e. al, " Comparative efficacy of various methods of laser therapy in patients with acute viral hepatitis B," Terapevticheskii arkhiv, vol. 73, no. 11, pp. 26-30, 2001. 
[5] T. N. Ovsyannikova, "Effect of low intensity laser irradiation on rat liver mitochondria," in 4th International Conference on Advanced Optoelectronics and Lasers. IEEE, 2008.

[6] A. A. Baigaliev, "The application of pulsed infrared laser radiation with autoresonant amplification for the treatment of patients with acute viral hepatitis B," Voprosy kurortologii, fizioterapii, i lechebnoi fizicheskoi kultury, no. 6, pp. 24-25, 2010.

[7] N. M. Burduli, "The influence of low-intensity laser radiation on the vascular endothelium function and the cytokine system in patients with chronic viral hepatitis," Voprosy kurortologii, fizioterapii, i lechebnoi fizicheskoi kultur, vol. 2, pp. 30-34, 2011.

[8] N.M. Burduli, "The influence of the low-frequency laser radiation on microcirculatory disorders in the patients presenting with chronic viral hepatitis," Voprosy kurortologii, fizioterapii, i lechebnoi fizicheskoi kultury, vol. 92, no. 4, pp. 25-29, 2015.

[9] S. A. Prahl, Light transport in tissue [Ph. D. Thesis], at Austin: The University of Texas, 1988.

[10] J. Schmitt, "Multilayer model of photon diffusion in skin," JOSA A, vol. 7, no. 11, pp. 2141-2153, 1990.

[11] J. Wang, "Monte Carlo modeling of light transport in multi-layered tissues in standard C," The University of Texas, MD Anderson Cancer Center, Houston, 1992.

[12] M. Keijzer, "Light distributions in artery tissue: Monte Carlo simulations for finitediameter laser beams," Lasers in surgery and medicine , vol. 9, no. 2, pp. 148-154, 1989.

[13] S. T. e. a. Flock, "Monte Carlo modeling of light propagation in highly scattering tissue-I: Model predictions and comparison with diffusion theory," EEE transactions on bio-medical engineering, vol. 36, no. 12, pp. 1162-1168, 1989.

[14] L. J. Wang, "MCML—Monte Carlo modeling of light transport in multi-layered tissues.," Computer methods and programs in biomedicine, vol. 47, no. 2, pp. 131-146, 1995.

[15] S. A. Prahl, "A Monte Carlo model of light propagation in tissue. Dosimetry of laser radiation in medicine and biology," International Society for Optics and Photonics, vol. 10305, p. 1030509, 1989.

[16] J. W. Gardner, "Monte Carlo simulation of light transport in tissue: unscattered absorption events," Applied optics, vol. 33, no. 13, pp. 2743-2745, 1994.

[17] T. J. Pfefer, "Adaptable three-dimensional Monte Carlo modeling of imaged blood vessels in skin In: Laser-Tissue Interaction VIII," International Society for Optics and Photonics, vol. 2975, pp. 2-13, 1997.

[18] R. H. Zubal, "Voxel based Monte Carlo calculations of nuclear medicine images and applied variance reduction techniques," Image and Vision Computing, vol. 10, no. 6, pp. 342348, 1992.

[19] W. L. Klose, "Light transport in biological tissue based on the simplified spherical harmonics equations," Journal of Computational Physics, vol. 220, no. 1, pp. 441-470, 2006.

[20] T. Vo-Dinh, J. Mobley and V. V. Tuchin, "Optical properties of tissue," in Biomedical photonics handbook: biomedical diagnostics, CRC press, 2014, pp. 46-145.

[21] V. G. Welch, Optical-thermal response of laser-irradiated tissue, New York: Springer, 2011.

[22] J. W. Cheong, "A review of the optical properties of biological tissues," IEEE journal of quantum electronics, vol. 26, no. 12, pp. 2166-2185, 1990.

[23] T. I. Karu, "The science of low power laser therapy," Gordon and Breach Scientific Publications, London. UK, 1998. 
[24] T. W. Weber, "The intravenous laser blood irradiation. Introduction of a new therapy," Lasers in Medicine, Science and Praxis, pp. 664-706, 2007.

[25] W. J. Kneebone, "Immune-modulating effects of therapeutic laser," Practical Pain Manag, vol. 10, no. 9, 2014. 